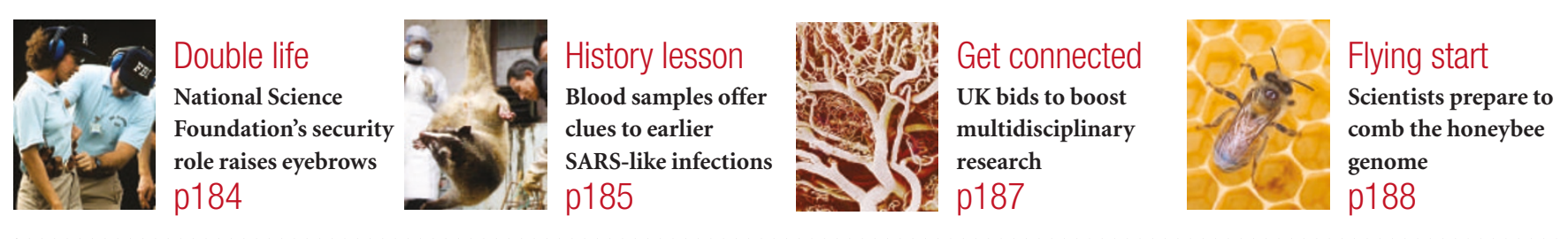

\title{
Robotic missions set to benefit as US takes aim at the Moon
}

Tony Reichhardt, Washington

A US push to send astronauts back to the Moon would require a series of robotic precursor missions that could reinvigorate lunar science, say researchers working in the field.

The human-spaceflight plan, which was due to be announced by President Bush this week, won't be driven primarily by lunar science - its main goal will be to prepare the way for deep-space exploration. "Going back to the Moon can't be just science-driven. There have to be broader goals than that," says Jeffrey Taylor, a planetary scientist at the University of Hawaii in Honolulu.

Nonetheless, some branches of space science could benefit greatly if the effort takes off. In particular, the initiative could lend impetus to unmanned lunar-exploration projects already on the drawing board.

Taylor and Paul Spudis, a planetary scientist at Johns Hopkins University's Applied Physics Laboratory in Baltimore, for example, are collaborating on a proposal for a robotic mission to collect samples from the Moon's south pole and return them to Earth by 2010. Dubbed 'Farside', their concept will compete with other mission proposals submitted to NASA's New Frontiers programme next month. If selected, the mission would cost up to $\$ 700$ million. The best reason for sending astronauts to the Moon is to "learn to live off the planet", says Spudis. Proponents say that Farside would help architects of the manned mission to meet that goal.

Another team, led by lunar researcher Michael Duke of the Colorado School of Mines and involving NASA's Jet Propulsion Laboratory at Pasadena, California, will submit a competing proposal for the lunar sample mission called 'Moonrise'.

Before astronauts venture onto the Moon's surface, Duke envisages that another robotic lander would be needed to prospect for ice near the poles and identify regions of permanent shadow and sunlight. Previous lunar orbiters have detected hydrogen in the Moon's soil, but its form is not known. If it is held in ice it could be used to produce drinking water and fuel for lunar explorers, and converting it would be a research topic at a future lunar base, Spudis predicts.

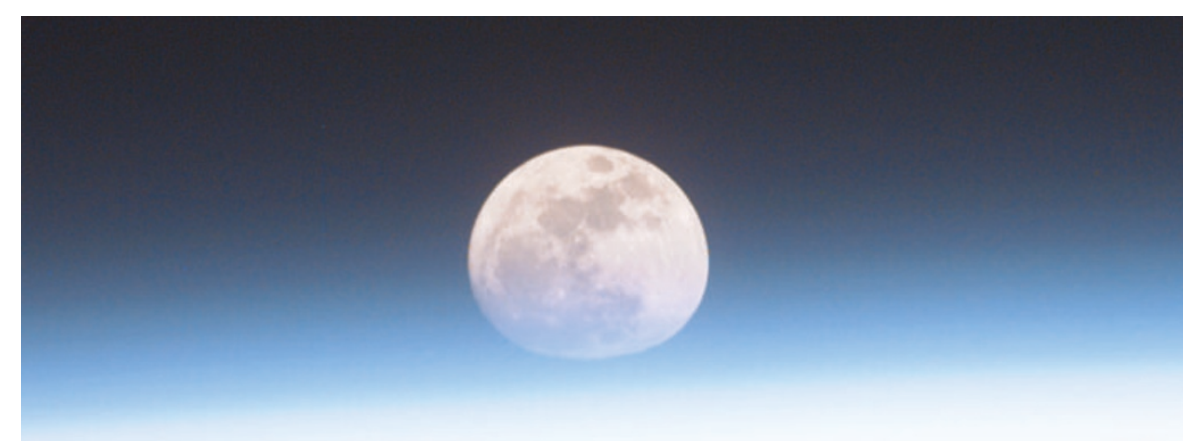

Return trip: US plans to send astronauts back to the Moon have met with a mixed response.

Other possible scientific investigations by robots or astronauts include systematic studies of small craters that might reveal the history of impacts from meteorites and other space debris, which may have a bearing on past mass extinctions on Earth. Astronaut geologists could also collect meteorites blown onto the Moon's surface from Earth and other planets in the distant past. By one estimate, there could be as much as 200 kilograms of terrestrial material on each square kilometre of the Moon's surface.

Whether a new manned space programme will now unfold in the United States remains an open question. Editorial writers and some Democratic presidential candidates immediately attacked the project as fiscally irresponsible when an outline of it was leaked last week. Others, including Sherwood Boehlert (Republican, New York), chairman of the House Committee on Science, offered cautious support.

Bush cabinet members appeared on television over the weekend to stress the plan's frugality. It is expected to involve an increase of about $\$ 800$ million, or $5 \%$, in NASA's annual budget for several years, but most of its funding would come from the rapid phasingout of the space shuttle, which costs NASA \$4 billion each year to fly. Another way to make the plan more affordable would be to rely on commercial Delta and Atlas rockets that have either already flown or are in development.

Reaction from scientists has also been mixed. While some worry that the programme could squeeze NASA's budget for areas such as astronomy, others point out that space-science spending rose sharply while the International Space Station was being built. Funding of space science and human exploration "is not a zero-sum game", says Wesley Huntress, a planetary scientist at the Carnegie Institution of Washington and former head of space science at NASA.

One of many questions facing the proposed programme is how the space station will fit in with it. Huntress and others told Congress in October that the station has little role to play in future human voyages to the Moon and Mars. But Spudis says that it might be smart politics for NASA to make use of the still-unfinished laboratory, perhaps even using it as a staging post on the way to the Moon. 